\title{
RPMGF: no limiar de um novo ano
}

Tiago Maricoto*

A medicina geral e familiar (MGF) é por excelência uma disciplina académica que ultrapassa largamente a sua vertente clinica e comunitária, ${ }^{1}$ em Portugal como no mundo. A Revista Portuguesa de Medicina Geral e Familiar (RPMGF), publicada ininterruptamente desde 1984, tem corporizado de forma indelével esta vertente científica na comunidade médica portuguesa.

Há cerca de quatro anos a RPMGF assumiu uma nova estrutura, separando a direção das tarefas editoriais, ${ }^{2}$ o que permitiu um conjunto de mudanças incomparáveis na sua história. Introduziu-se um novo modelo de gestão e liderança, com profissionalismo e o envolvimento de uma equipa editorial de qualidade técnica e científica, escolhida da vanguarda da MGF portuguesa. ${ }^{3-4}$ Estabeleceram-se objetivos alcançáveis e realistas para a RPMGF, criou-se um núcleo coordenador incluindo o editor-chefe e dois editores executivos, dinamizou-se o trabalho de equipa na perspetiva de uma maior mobilidade, permitindo entradas e saídas sem comprometer a estabilidade, reforçou-se o corpo de revisores, reformulou-se o processo editorial, atualizaram-se as normas de publicação, ${ }^{5}$ o que gerou ganhos significativos na redução dos tempos de revisão e de aceitação dos artigos. ${ }^{6-7}$ Chegados a 2020, e apesar de um ano atipicamente marcado por uma pandemia sem precedentes na nossa história recente, a RPMGF conquistou e alcançou marcos importantes:

- Reestruturação administrativa e funcional, desenvolvendo e reforçando o corpo editorial e otimizando o processo editorial. Reduziu-se o tempo de validação administrativa dos artigos para menos de cinco dias.

- Renovação do Conselho Científico nacional da revista, uma peça basilar, capital e garantia da idoneidade, rigor e creditação.

*Editor-Adjunto da RPMGF

USF Aveiro-Aradas, ACeS Baixo Vouga

Faculdade de Ciências da Saúde, Universidade da Beira Interior
- Criação de um Conselho Científico internacional (International Board), como ferramenta de internacionalização e creditação da revista por todo o mundo.

- Implementação de um processo contínuo de formação de novos editores, permitindo alargar a equipa editorial, com um novo conceito de inclusão regular de editores júniores em processo de formação. Incluiram-se mais 33 editores, 23 deles júniores, que progressivamente foram assumindo maior capacidade técnica e autonomia no processo editorial e plenamente integrados na equipa.

- Alargamento do plano de indexação para maior visibilidade e impacto. Manteve-se a indexação na SciELO, que atualmente é uma das base de dados da Web of Science, e no Index de Revistas Médicas Portuguesas. A associação à Crossref possibilitou a atribuição do DOI (digital object identifier) a cada artigo, um código único de identificação de documentos em redes digitais, e a presença no Google-Scholar. Conseguiu-se o reconhecimento no Directory of Research Journals Indexing, no Index Copernicus, na EBSCO e na ICI Journals Master List.

- Transição para a era digital, com a publicação em versão digital exclusiva.

- Publicação dos resumos dos principais e mais credenciados eventos científicos da Associação Portuguesa de Medicina Geral e Familiar, valorizando e premiando a atividade cientifica dos médicos de família.

- Alargamento da equipa de revisores, com redução significativa do tempo médio de revisão, um investimento precioso para o futuro da revista. Triplicou-se a equipa de revisores ativos, chamando novos elementos para colaborar e valorizar a revista. Reduziu-se o tempo médio de revisão de mais de um ano para cerca de três meses na atualidade.

A RPMGF está melhor do que nunca. Criaram-se condições para alavancar a RPMGF aos mais altos padrões de qualidade e desafiam-se todos a acompanhar 
este percurso: uma dinâmica vanguardista, uma atitude profissional e uma visão internacional. Temos consciência do caminho árduo que ainda se espera para garantir a indexação nas principais bases de referências internacionais, como a MEDLINE, a Scopus e a Embase. O caminho é a qualidade e o desafio é para os médicos de família. São necessários mais e melhores artigos originais, consolidando a imensa produção científica que é visível nos congressos, envolvendo a formação médica pré-graduada, os internatos de especialidade, a academia, os centros de investigação e as redes colaborativas nacionais e internacionais. A RPMGF crescerá com o crescimento científico da MGF, alicerçado em estruturas de investimento sólido e sério, onde a Associação Portuguesa de Medicina Geral e Familiar pode ter um papel decisivo.

Começa mais um ano, depois de um 2020 marcado pela pandemia da COVID-19, que a todos atingiu. Mais do que recordações nostálgicas de um passado que já lá vai, olhamos para o futuro com expectativa e entusiasmo, por mais e melhor investigação clínica em medicina geral e familiar.

\section{REFERÊNCIAS BIBLIOGRÁFICAS}

1. Allen J, Gay B, Crebolder H, Heyrman J, Svab I, Ram P. The European definition of general practice/family medicine [Internet]. In: SemFYC,
EURACT. Barcelona:WONCA; 2011. Available from: https://www.woncaeurope.org/file/520e8ed3-30b4-4a74-bc35-87286d3de5c7/Definition\%203rd\%20ed\%202011\%20with\%20revised\%20wonca\%20tree. pdf

2. Nogueira R.A partilha do conhecimento num novo ciclo [Sharing knowledge in a new cycle]. Rev Port Med Geral Fam. 2017;33(3):170. Portuguese

3. Hespanhol AP. Um ponto de situação do novo modelo editorial da revista [The current situation of the new editorial model of the RPMGF]. Rev Port Med Geral Fam. 2017;33(5):310-2. Portuguese

4. Hespanhol AP. Contributo de novo modelo editorial da revista para a formação e a investigação em medicina geral e familiar [Contribution of a new editorial model for continuous education and research in general and family medicine]. Rev Port Med Geral Fam. 2017;33(4):242. Portuguese

5. Equipa Editorial. Normas para submissão de artigos à Revista Portuguesa de Medicina Geral e Familiar [Publication guidelines of 'Revista Portuguesa de Medicina Geral e Familiar']. Rev Port Med Geral Fam. 2018;34(3):173-80. Portuguese

6. Santos P, Maricoto T, Hespanhol A, Nogueira R. O novo ciclo da medicina geral e familiar [The new cycle of general family medicine]. Rev Port Med Geral Fam. 2018;34(3):123. Portuguese

7. Hespanhol A, Maricoto T, Santos P, Nogueira R. O primeiro ano em revisão do novo ciclo da medicina geral e familiar: mudanças e perspetivas. Rev Port Med Geral Fam. 2019;34(6):351-2.

\section{ENDEREÇO PARA CORRESPONDÊNCIA}

E-mail: tiago.maricoto@gmail.com

https://orcid.org/0000-0002-4201-9565 